\title{
Análisis de la estructura lógica del delito de falsificación de documentos
}

Analysis of the Logical Structure of the Crime
of Forgery

Segundo Félix Quesquén Ríos* http://dx.doi.org/10.21503/lex.v13i16.857

* Abogado por la Universidad Inca Garcilaso de la Vega, máster en Derecho Civil por la Universidad Alas Peruanas. Estudiante del Doctorado en Derecho en la Universidad Nacional Mayor de San Marcos. Diplomado por el Ilustre Colegio de Abogados del Callao en "Derecho Penal y Económico: Delitos Tributarios y Aduaneros"; "Diplomado Especializado en el Código Procesal Penal del 2008 y Técnicas de Litigación Oral” por la UAP. Catedrático de pregrado y postgrado de la UAP. E-mail:s_quesquen@doc.uap.edu.pe 


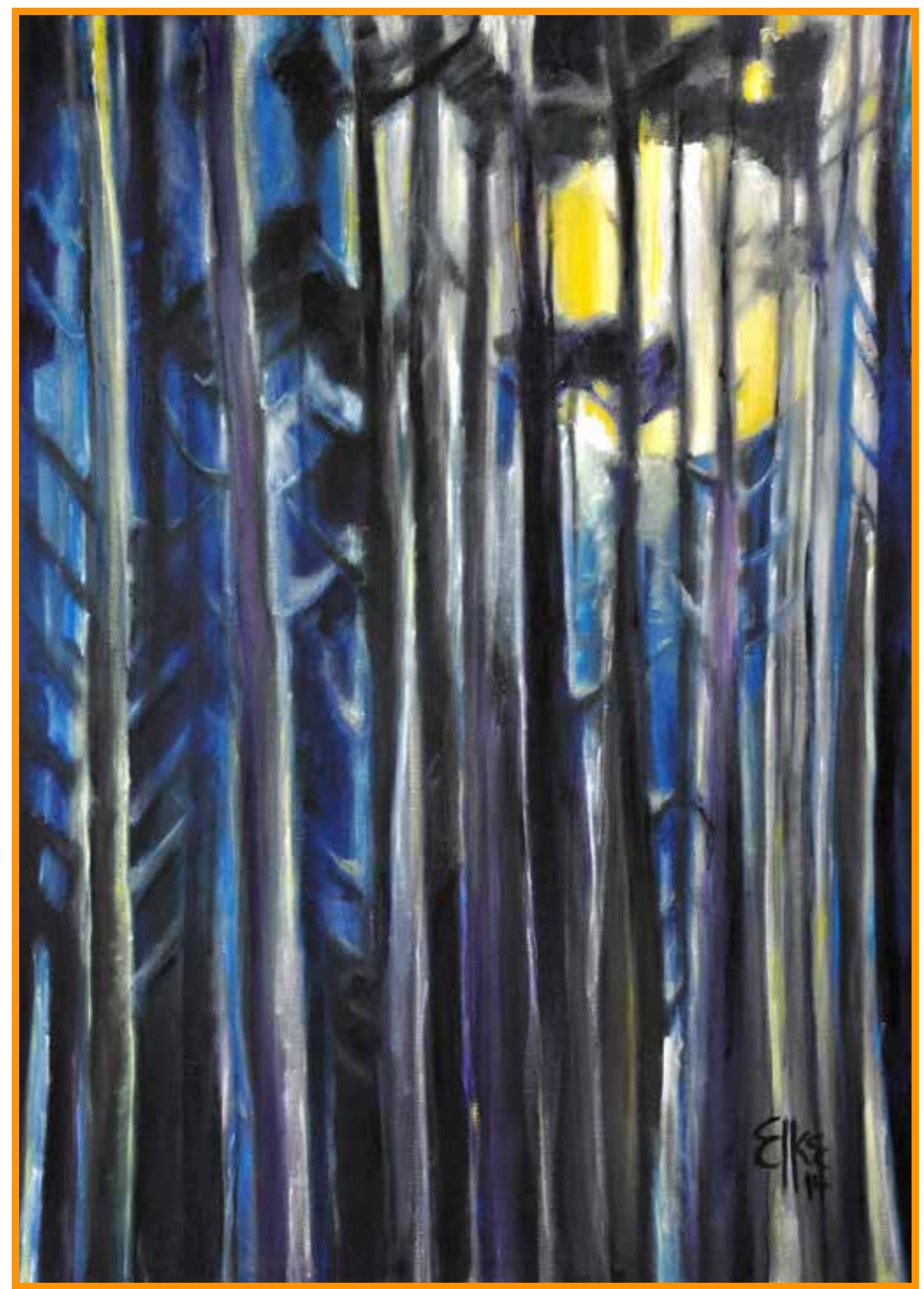

Nocturno: Los poetas y la luz. Serie “Árboles". Óleo $(105 \times 80 \mathrm{~cm})$, año 1 991. Elke McDonald 


\section{RESUMEN}

El presente artículo tiene como objetivo analizar el delito de falsificación de documentos previsto en el Art. $427^{\circ}$ del Código Penal Peruano, desde una óptica de la lógica jurídica, encontrando que el delito en mención en su estructura presenta deficiencias por la mala redacción de la proposición normativa en el supuesto de hecho, donde no se ha establecido desde un contexto lógico, por parte del legislador, cuál es el bien o bienes jurídicos de protección por la normatividad penal, lo que no permite una correcta administración de justicia y sanción al sujeto activo del delito, quedando su accionar delictivo impune, situación que se ha advertido por parte del operador jurídico (abogados, jueces y fiscales) desde la entrada en vigencia del Código Penal de 1991, manteniendo silencio cómplice el legislador respecto a esta problemática jurídica al no haberse ocupado de su reingeniería jurídica del delito bajo comentario. A través del presente artículo se busca promover la conciencia del legislador de establecer cuál es bien o bienes jurídicos sujetos de protección penal, como delimitar con claridad y exactitud lo que debe entenderse por documento dentro del ámbito penal.

Palabras clave: estructura lógica, delito, falsificación de documentos.

\section{ABSTRACT}

This article aims to analyze the crime of forgery referred to in Art. 427th of the Peruvian Penal Code, from the perspective of legal logic, finding that the crime in question has weaknesses in its structure by poor drafting of the proposal rules on the assumption made, where it has not been established from a logical context, by the legislator, what is good or legal rights protection by criminal legislation, which does not allow the proper administration of justice and punish the perpetrator crime, his criminal actions being unpunished situation warned by the legal operator (lawyers, judges and prosecutors) from the entry into force of the Penal Code of 1991, keeping silent complicity the legislator regarding this legal problem by failing busy reengineering legal offense under comment. Through this article seeks to promote awareness of the legislature to establish what is good or goods subject of criminal legal protection, as clearly and accurately define what is meant by document inside the penalty area.

Key words: logic structure, crime, forgery. 



\section{INTRODUCCIÓN}

La condición de docente del curso de Lógica Jurídica me ha permitido analizar la norma jurídica con una visión diferente al netamente jurídico-legal respecto al Art. $427^{\circ}$ del Código Penal, empleando la lógica jurídica como un instrumento de la ciencia jurídica, para entender el criterio de verdad que ha considerado el legislador nacional para tipificar el delito de falsificación de documentos, encontrando que los estudios del Derecho Penal al día de hoy no han establecido un consenso referente. ¿Cuál es la institución sociojurídica que realmente se protege en el delito de falsedad documental? Esta es una problemática que no es ajena a la actividad judicial, y por ende la existencia de fallos contradictorios al no existir propuestas uniformes respecto a la determinación de la figura del bien jurídico en las falsedades documentales, que permitan fijar los límites de lo punible. De esto se aprovecha el agente activo del delito de seguir cometiendo este tipo de delitos a sabiendas de que es muy probable que no se le encuentre responsable penalmente, bajo el principio constitucional previsto en el Art. $139^{\circ}$, Inc. 11 de la Constitución Política del Estado, de que "la duda favorece al reo", por no encontrarse debidamente delimitado el bien jurídico sujeto de protección penal. Esta es una de las causas por la que a diario se atenta contra el patrimonio ajeno mediante la falsificación documentaria, poniendo en riesgo la protección del patrimonio del legítimo propietario o poseedor, constituyéndose el delito bajo análisis en pluriofensivo, por atacar otros bienes jurídicos como el de seguridad en el trafico jurídico, y perjudicando de esta forma, además del sujeto pasivo — propietario o poseedor del patrimonio-, también a la sociedad y el Estado, que no encuentra la forma como el Derecho Penal funcione como medio de control social formal, por lo que se hace necesario que el legislador uniformice criterios respecto al bien jurídico a proteger y de esta forma modificar la proposición normativa, buscando alcanzar una correcta estructura de la norma jurídica en comento, perfeccionando el criterio de verdad, sin el cual no se puede alcanzar la justicia 


\section{ESTRUCTURA DE LA NORMA JURÍDICO-PENAL ${ }^{1}$}

Estructura lógica. Como toda norma jurídica corriente, la norma penal suele constar de un supuesto de hecho y de una consecuencia jurídica, y tiene la forma de una proposición en la que el supuesto va enlazado a la sanción por una cópula; esta terminología es preferible a la de precepto y sanción, que recuerda la concesión monista de los imperativos de donde proviene. Sin embargo, a diferencia de otras reglas jurídicas, el supuesto de hecho de la norma penal aparece integrado por un tipo penal a veces denominado impropiamente "hecho punible" o "delito", entre tanto, la consecuencia jurídica está conformada por una pena o una medida de seguridad.

Norma jurídica y ley penal. El Derecho Penal está constituido por un conjunto de normas, las mismas que están formadas por un supuesto de hecho o presupuesto y una consecuencia jurídica. Rodríguez Deveza y Serrano Gómez justifican el empleo de esta terminología a la de precepto y sanción.

La norma primaria y la norma secundaria. Como anota Peña Cabrera, en la estructura lógica de la norma se advierte la diferencia entre presupuesto y consecuencia jurídica, pero esa distinción adquiere validez en la medida en que se avizoren la norma primaria y la norma secundaria. Efectivamente, en el plano enteramente lógico toda ley penal contiene dos aspectos:

a. Directamente la ley formula un mandato hipotético dirigido al Juez para que este aplique la pena conminada.

b. En forma inmediata y deducida de la ley penal hay una norma dirigida al ciudadano ordenándole y prohibiéndole la conducta que interesa; esa norma se desprende de la norma mediata de la redacción hipotética de la ley penal, de modo que no procede a esta ni es condición de su vigencia.

En cuanto al carácter de la norma secundaria, esta constituye efectivamente un imperativo dirigido al Juez para que efectúe la aplicación de una sanción al trasgresor de la norma primaria. La discusión se centra en torno a la naturaleza de la norma primaria, pues hay quienes ven en ella un carácter eminentemente operativo, como otros que afirman que procede la naturaleza de un juicio de valor.

La concepción imperativa de la norma. La norma primaria como imperativo se dirige al ciudadano para que no realice la acción descrita en la ley penal. La norma así entendida

Santos Eugenio Urtecho Benites. El perjuicio en los delitos de falsedad documental. Consecuencias de la proposición ambigua del tipo legal e interpretación teórica deficiente. Segunda edición, corregida, aumentada y actualizada. Lima, Perú: Idemsa, 2015. 
establece un orden de convivencia social, ya que los miembros de la sociedad no podrán quebrantar la prohibición sin dejar de recibir por ello una sanción penal. Así cada persona de la comunidad espera que los otros desarrollen un comportamiento determinado que en ningún modo sea contrario al enunciado de la norma (ver p. 177).

\section{EL DERECHO PENAL COMO MEDIO DE CONTROL SOCIAL ${ }^{2}$}

El Derecho Penal constituye uno de los medios de control social existentes en las ciudades actuales. La familia, la escuela, la profesión, los grupos sociales son también medios de control social, pero poseen un carácter informal que lo distingue de un medio de control jurídico altamente formalizado como es el Derecho Penal. Como todo medio de control social, este tiende a evitar determinados comportamientos sociales que se reputan indeseables, acudiendo para ello a la amenaza de imposición de distintas sanciones para el caso de que dichas conductas se realicen; pero el Derecho Penal se caracteriza por prever las sanciones en principio más graves, las penas y las medidas de seguridad, como forma de evitar los comportamientos que juzga especialmente peligrosos, los delitos. Se trata, pues, de una forma de control social lo suficientemente importante como para que, por una parte, hayan sido fundamentales del poder estatal, que desde la Revolución Francesa se considera necesario delimitar con la máxima claridad posible como garantía del ciudadano. De ahí que el poder punitivo, reservado al Estado, solo pueda ejercerse de acuerdo con lo previsto por determinadas normas legales, a aprobar por los representantes del pueblo en los países democráticos. Tales normas, que constituyen el Derecho Penal, deben determinar con la mayor precisión posible qué conductas pueden considerarse constitutivas de delito y qué penas pueden sufrir quienes las desarrollen. Es lo que conocemos con la expresión "principio de legalidad", y en ello consiste el carácter eminentemente formalizado que distingue al Derecho Penal de otros medios de control social.

La fe pública. Entendida como garantía que otorga el Estado a sus administrados, asume que los hechos que interesan al Derecho son verdaderos y auténticos, por cuanto en la realidad social existen una serie de hechos y actos con relevancia jurídica que deben ser creídos y aceptados como verdad oficial, en razón de existir normas legales que así lo establecen, al encontrarse investidas de la fe pública y haber intervenido un agente autorizado por el Estado

La fe pública, conforme a lo anteriormente desarrollado, constituye un bien jurídico colectivo, en razón de que con su vulneración no solo se afecta la fe personal de una persona o de un grupo de personas en un caso concreto, sino de toda la sociedad e incluso al Estado. Por ende, urge que se materialice su protección a través de una norma jurídica que materialice la

Santiago Mir Puig. Derecho Penal. Parte general. 4ta. edición corregida y puesta al día con arreglo al Código Penal de 1995. Barcelona: PPU S. A., 1996. 
certeza y validez del documento, mediante la implementación de una correcta y prolija política criminal por parte del Estado, que permita uniformizar criterios sobre su regulación jurídica, teniendo en cuenta además los avances tecnológicos de los que hacen uso los delincuentes en la comisión del delito de falsificación de documentos, en aras de garantizar la seguridad del tráfico jurídico del patrimonio y que de esta forma los justiciables alcancen la paz social, confiando en la garantía que le otorga el Estado, como es la fe pública.

\section{DELITOS CONTRA LA FE PÚBLICA}

Concepto de falsedad. Escriche, refiriéndose al delito de falsedad, sostiene que "es la imitación, suposición, alteración, ocultación, supresión de la verdad hecha maliciosamente en perjuicio de otro". ${ }^{3}$ Bramont Arias, a su vez, precisa que la falsedad es toda alteración de la verdad. La noción que puede darse de la falsedad es negativa; falsedad es lo que va contra la fe pública. En el uso corriente del lenguaje parece que indican lo mismo falsedad que falsificación, y así igualmente se dice falsario que falsificador, falsificación que falsedad. Sin embargo, tienen un significado distinto en el Derecho Penal ${ }^{4}$. Debemos resaltar que la falsedad siempre acompaña constantemente a todos los fraudes.

Falsedad y falsificación. Según hace notar Groizard, citado por Muñoz Conde, ${ }^{5}$ la falsificación supone siempre falsedad, al paso que la falsedad no identifica la falsificación: la una es el género, la otra una de las especies de aquel. Para que la falsificación resulte es necesaria la previa existencia de un documento o de un objeto verdadero, que mediante ciertos procedimientos se altera y, al alterarse, se falsifica. La falsedad indica por el contrario la comisión de un hecho o la ejecución de un acto en el que no se expresa la verdad, sino que a sabiendas se emiten conceptos no verdaderos. La falsedad se comete sin necesidad de la existencia previa de un objeto, al paso que la falsificación no se produce sin ella.

\section{Formas típicas de falsedad}

Falsedad material. Las características comunes de la falsedad material son: a) La conducta, que consiste en el acto de hacer o adulterar o suprimir o destruir; b) El objeto material, que es el documento sobre el cual la conducta criminal recae; c) La voluntad del hecho, con conciencia de la falsedad. Por eso, la falsedad material puede efectuarse por el hecho de hacer un documento falso en todo o en parte, por el hecho de adulterar un documento verdadero, y por suprimir o destruir, en todo o en parte, un documento. Nuestro Código Penal lo contempla en el art. $427 .{ }^{6}$

3 Escriche, citado por Luis A. Bramont-Arias. "Falsedad”, en Enciclopedia Jurídica OMEBA. Tomo XI. Buenos Aires, 1979, p. 850 .

Luis Bramont-Arias. Op. cit. p. 849.

Muñoz Conde. Derecho Penal. Parte especial. Valencia: Tirant lo Blanch, 1999, pp. 607-608.

6 Santos Eugenio Urtecho Benites. Op. cit. 
Falsedad ideológica. La falsedad ideológica o ideal es la que recae sobre el contenido ideal de un documento público, o sea, cuando en un documento autorizado por las autoridades legales y por funcionarios competentes, se hacen constar hechos o atestaciones que no son verdaderos. ${ }^{7}$ La falsedad ideológica se caracteriza por la violación de la obligación de declarar la verdad por parte del sujeto que redacta el documento.

El principio de última ratio. Para el ilustre Peña Cabrera, ${ }^{8}$ citado por Urtecho Benites, los instrumentos de los que se vale el Derecho Penal para la protección de los bienes jurídicos suelen ser más severos que otras ramas del ordenamiento jurídico, por lo que la utilización de dichos mecanismos solo ha de ser posible cuando la sociedad no puede controlar graves conflictos, siendo uno de esos recursos estatales la pena. Pero esta necesidad no basta para que la pena sea utilizada, sino que esta debe ser proporcional y deberá encuadrarse dentro de un ámbito legal garantista.

Esta "amarga necesidad" que constituye la pena por las consecuencias que conlleva para el individuo, hace que solo se recurra a ella como ultima ratio, es decir, como el último recurso a emplear por no existir otros medios más eficaces. Pero la intervención punitiva estatal no se realiza frente a toda situación, sino solo a hechos que la ley penal ha determinado específicamente (carácter fragmentario), por que la pena constituye un instrumento subsidiario.

\section{EL BIEN JURÍDICO GENÉRICO}

Para Binding, bien jurídico es todo estado valorado por el legislador, ínsito en toda norma jurídica. En su concepción puede observarse que cada norma jurídica es portadora de su propio bien jurídico, resultando, en consecuencia, que la norma y bien jurídico son conceptos indesligables. La mera desobediencia al mandato normativo es, a su juicio, señal inequívoca de la lesión del mismo.?

\section{EL BIEN JURÍDICO EN LOS DELITOS DE FALSEDAD DOCUMENTAL}

La sociedad contemporánea se caracteriza por la presencia de una alta cuota de dinamismo y complejidad en el tema de los contactos interpersonales, los cuales hoy suelen diluirse y desarrollarse en amplios campos de anonimato, situación opuesta a lo vivido por los primeros grupos sociales, caracterizados por reunir un limitado número de miembros, y en el que "transmisión oral e incluso los testigos eran suficientes para mantener tales relaciones". ${ }^{10}$ Lógicamente que en el panorama actual de las interrelaciones sociales, tales medios carecen

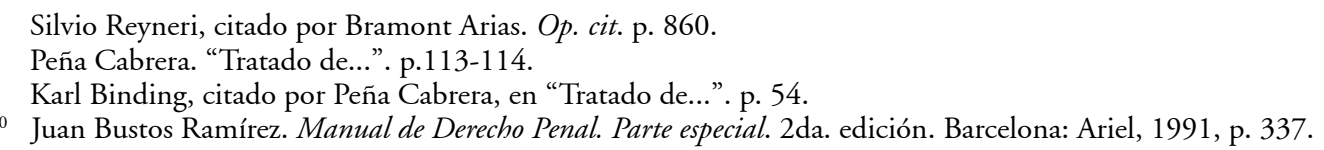


de efectividad, por lo que se han buscado otros instrumentos como los documentos, sobre los cuales es factible materializar aspectos de la relación de los sujetos y que pueden perdurar en el tiempo, así como servir de medio de prueba y otorgar garantía a los ciudadanos. Es por esto, que surgió la necesidad de otorgarle protección a los documentos, mediante su inclusión en los tipos de la parte especial de los Códigos Penales, con la finalidad que de lo que ahí consta no se pueda ver eliminado o adulterado mediante los actos de falsificación. Sin embargo, los estudiosos del Derecho Penal no han podido llegar hasta la actualidad a un consenso sobre cuál es la institución sociojurídica que realmente se protege en el delito de falsedad documental, pues desde que se inició la discusión, han sido propuesto un sinnúmero de soluciones, pero que no han logrado evadir las críticas a las que han sido expuestas. Esta ausencia de unanimidad en la doctrina conduce a que no se haya tenido en cuenta que una concreta y previa determinación de la figura del bien jurídico en las falsedades documentales no solo coadyuvaría a fijar los límites de lo punible, sino que también ayudaría a un adecuado entendimiento de los demás componentes del tipo objetivo. ${ }^{11}$

a. El derecho a la verdad. El derecho a la verdad puede ser tomado como un precedente histórico del concepto de fe pública. En los inicios del tratamiento de la falsificación, esta era colocada en un mismo plano junto a la estafa, lo que originó cierta confusión entre ambos delitos. En la búsqueda por diferenciar falsedad de estafa, se llegó a considerar que en aquella solo se trataba de la lesión del derecho a la verdad mientras que en la estafa se atentaba además contra la propiedad. ${ }^{12}$

Hay que relacionar la fe pública con la idea de la verdad, pero no en el sentido de un derecho a la verdad, sino de veracidad jurídica (que no es la verdad filosófica, ni tampoco lo contrario a mentira, sino solo dotado de formas capaces de darle validez jurídica), que implica necesariamente su objetivización, esto es, su reconocimiento por todo de modo objetivo. De ahí su vinculación desde antiguo con el documento, y por eso también que tal veracidad jurídica aparezca indisolublemente ligada al concepto de autenticidad del objeto, justamente para que pueda dar fe pública. Con ello también se logra diferenciar la fe pública de la administración de justicia, del problema de los medios de prueba. Es cierto que ambos conceptos aparecen muy ligados, ya que justamente el objeto que objetiviza puede ser medio de prueba, pero no necesariamente su sentido y objetivo es el proceso. Su sentido es mucho más amplio, es servir a la mantención de las interrelaciones entre los sujetos, y tiene un carácter funcional. Mientras los grupos sociales eran pequeños, la transmisión oral y los testigos eran suficientes para la mantención de tales relaciones. Pero a medida que crecen los grupos sociales, sus actividades tenían efectos más allá de sus vidas, por lo que el testimonio

11 David Rosales Artica. "El delito de falsificación de documentos. Bien jurídico y objeto material de la acción”. Actualidad Jurídica, tomo 160 (marzo 2007).

12 Ibid. 
resultaba un instrumento inefectivo para la vida social (sin perjuicio de su importancia en el proceso). De ahí el surgimiento del documento y otros objetos que den perpetuidad a la interrelación entre los sujetos y que además no sean susceptibles de ser transformados con el tiempo (como sucede con la transmisión oral o con los testimonios), sino que por el contrario den garantía a la fijeza. Por eso surge la necesidad de su protección, con el objeto de que no pierda las características esenciales para las interrelaciones sociales, que justamente se pueden ver eliminadas a través de los actos de falsificación. ${ }^{13}$

b. La fe pública. En el Derecho Romano no se conocía la falsedad documental; estos delitos aparecen con la Lex Cornelia testamentaria nummaria, llamada después Lex Cornelia de Falsis, cuando se amplió su contenido con cierto número de senadoconsultos y constituciones relativas todos ellos a delitos de falsedad. La Lex Cornelia testamentaria nummaria apareció para reprimir los frecuentes delitos en materia de falsedad de testamento y moneda.

El bien jurídico protegido es "fe pública", expresión que, como observa Carrara, no debe interpretarse como fidelidad en el mantenimiento de una obligación contraída, sino en el sentido de confianza. Algunos autores consideran como fe pública solamente la impuesta por la ley, pero tal opinión no es aceptable, pues la fe pública reconoce a determinados documentos destinados a probar hechos originarios de consecuencias jurídicas. Documento es una manifestación de voluntad, en forma escrita, capaz de probar hechos de transcendencia jurídica. Pero no es preciso que esté relacionado o confeccionado con la finalidad de servir de prueba; basta que sea apto para ello. ${ }^{14}$

Refiere Rosales Ártica que el fundamento de la fe pública como bien jurídico en la falsedad documental no es otro que el de la confianza que, innatamente, el ciudadano deposita en determinadas formas o signos. A partir de aquí, se entiende que lo que se protege es la falsedad documental. Esto se deriva de la confianza de los ciudadanos — por medio de la costumbreen las características de ciertos objetos que les permiten ser adecuadas para satisfacer las necesidades que exigen las relaciones sociales o la instrumentación de estos en el ámbito jurídico. A pesar de la aceptación que esta idea ha tenido no solo en las legislaciones penales de diversos países, sino también en la doctrina penal, se puede decir que la fe pública hoy es solamente un marco general o punto de referencia común a todos los delitos de falsedad, pero demasiado vago e inconcreto para, por sí mismo, solventar las cuestiones planteada. Su enorme abstracción y generalidad la tornan como una idea no aceptable. Un análisis a profundidad de ellos nos permitirá constatar que la fe pública en el valor probatorio de los documentos adquiere formas diversas según la fuerza probatorio del documento. ${ }^{15}$

13 Juan Bustos Ramírez. Op. cit.

14 Eugenio Cuello Calón. Derecho Penal. Parte especial. Tomo II. Decimocuarta edición. Barcelona: Bosch, Casa Editorial S. A., 1980.

15 David Rosales Artica. Op. cit. 
c. Carácter pluriofensivo. Según Francisco Antolisei, nunca es fin en sí misma, sino que es una forma de defraudación, y medio para ofender determinados intereses. De allí que afirme que los delitos contra la fe pública sean delitos pluriofensivos, en el sentido de que siempre se dan dos ofensas: una que es común a este tipo de delitos, y otra que varía según los delitos que se cometen. La primera corresponde a la fe pública y la segunda al interés específico que es salvaguardado por la integridad de los medios probatorios. ${ }^{16}$

d. El valor probatorio de los documentos. Según Bindign, quien parte de la idea de considerar a los medios de prueba fuera del proceso, pero teniendo en cuenta su concreto contenido dentro del proceso, lo que se protege con la falsedad del documento es la seguridad de estas pruebas, pero fuera del proceso. Por ello se afirma que con la prueba se ha demostrado la existencia o no de un derecho o una obligación, y por ello no es el Juez su destinatario, sino la contraparte o cualquier persona cuando la prueba se practica fuera del proceso. ${ }^{17} \mathrm{Con}$ ello se resalta la importancia de ciertos documentos como medio de prueba, que garantizan la genuinidad y la veracidad de lo insertado en ellos.

e. La seguridad del tráfico jurídico. Según la doctrina moderna, la fe pública es el presupuesto de la seguridad en el tráfico jurídico. Debe diferenciarse en esta posición dos etapas: la primera que ve la seguridad jurídica como bien jurídico, y la segunda etapa en la cual se busca concretarlo, debido a la indeterminación y a su generalidad, tal como había pasado con la idea de fe pública. Desde esta perspectiva, según Donna y tal como está legislado en los códigos penales, no hay duda en afirmar que la seguridad jurídica aparece como una prolongación de la fe pública, con la cual tiene varios criterios en común. Lo positivo al tomar este bien jurídico es el abandono de las connotaciones psicológicas que tenía la fe pública, así como su vaguedad conceptual. Se pasa desde esta perspectiva a un concepto objetivo del bien jurídico, aunque respetando la idea de que sigue siendo ideal inmaterial. ${ }^{18}$

f. El carácter funcional del documento. Propuesta defendida por autores como Rheinek, Puppe, Samson en Alemania, Muñoz Conde en España, y a nivel nacional Castillo Alva y García Cantizana. De acuerdo a esta concepción, el bien jurídico protegido en las falsedades documentales es el mismo documento por considerarlo el objeto que cualifica y le otorga autonomía a la falsedad respecto de otras figuras delictivas, es decir, que esta teoría centra su atención en el mismo objeto material del delito, a saber el documento. El documento se convierte, de esta manera, en el interés amparado penalmente, elevándose a la categoría de elemento básico para el desarrollo de la sociedad. Así, si se comprende que el contenido del bien jurídico, en funcionalidad del documento, es el de servir al mantenimiento de las

16 Edgardo Dona. "El bien jurídico en los delitos contra la fe pública”. En Modernas tendencias en dogmática penal y política criminal, ed. Urquizo Olaechea. Libro de homenaje al doctor Juan Bustos Ramírez. Lima: Idemsa, año 2007.

7 Binding K., citado por Dona, Edgardo. Op. cit. p. 271.

18 Santos Eugenio Urtecho Benites. Op. cit. 
interrelaciones entre los sujetos, estaríamos hablando del carácter funcional del bien jurídico, cuyas premisas se edificarían y elaborarían a partir del mismo objeto de la acción, el rol y función que desempeña en el plano jurídico y social. Esta funcionalidad del documento se concretiza en las diversas misiones que tiene que cumplir en el tráfico jurídico, que son la de medio de prueba, la de perpetuación (dar perdurabilidad a las declaraciones contenidas en él) y la de garantía (se trata de un soporte que permite imputar a un autor concreto la declaración contenida en este). Esas funciones son, por otra parte, la causa de que el público confíe en los documentos y los utilice (fe pública). ${ }^{19}$

g. Toma de postura. Nuestra posición considera que el bien jurídico protegido es "fe pública”, pero en sentido colectivo, entendido como un sentido de confianza a esa garantía que nos otorga el Estado a sus administrados, sobre determinados hechos considerados como verdaderos y auténticos, con relevancia jurídica que son creídos y aceptados como verdad oficial, según el ordenamiento legal, por encontrarse investidos de la fe pública y al haber intervenido un agente autorizado por el Estado. De otro lado, al ser el delito de falsificación de documentos una forma de defraudación por la que, además, se ofenden otros bienes jurídicos distintos a la fe pública, consideramos que se trata de un delito pluriofensivo, que debe buscar la seguridad jurídica del trafico jurídico como una prolongación de la fe pública.

\section{EL DOCUMENTO EN LOS DELITOS DE FALSEDAD DOCUMENTAL}

Concepto de documento. ${ }^{20}$ De manera general se entiende como todo objeto elaborado por el ser humano, contentivo de signos con carácter de permanencia y relevancia jurídica. Su valor tiene por génesis la raíz latina docere, que significa enseñar, mostrar o hacer conocer algo, y reviste gran trascendencia social, por cuanto recoge la memoria histórica de una civilización.

En el campo jurídico y, en especial, en lo que atañe al Derecho probatorio, esta manifestación del pensamiento se entiende desde dos perspectivas: la amplia, referida a todo objeto o medio de prueba, y la restrictiva, fincada única y exclusivamente en el documento escrito.

De acuerdo con la concepción amplia o germánica, se le da carácter de documento a las piedras, los vestidos, las huellas de una pisada, los huesos, las estatuas, las edificaciones, las esculturas, los cuadros, y todo elemento probatoriamente relevante.

Para la concepción restrictiva o latina, la única forma que merece considerarse como documento es la escrita, que demanda su fijación en un medio idóneo, tangible y permanente, atribuible a un autor determinado y que contiene manifestaciones de voluntad de relevancia jurídica.

19 David Rosales Artica. Op. cit.

20 Yesid Viveros Castellanos. Falsedad ideológica. Bogotá, Colombia: Ediciones Doctrina y Ley Ltda., 2006, p. 11. 


\section{DELITO DE FALSIFICACIÓN DE DOCUMENTOS ${ }^{21}$}

Descripción Legal:

Art. $427^{\circ}$. El que hace, en todo o en parte, un documento falso o adultera uno verdadero que pueda dar origen a derecho u obligación o servir para probar un hecho, con el propósito de utilizar el documento, será reprimido si, de su uso puede resultar algún perjuicio, con pena privativa de libertad no menor de dos ni mayor de diez años y con treinta a noventa dias-multa si se trata de un documento público, registro público, título auténtico o cualquier otro transmisible por endoso o al portador y con pena privativa de libertad no menor de dos ni mayor de cuatro años, y con ciento ochenta a trescientos sesenta y cinco dias-multa, si se trata de un documento privado.

El que hace uso de un documento falso o falsificado, como si fuera legitimo, siempre que de su uso pueda resultar algún perjuicio, será reprimido, en su caso, con las mismas penas.

Bien jurídico protegido. El bien jurídico protegido es la funcionalidad del documento en el tráfico jurídico.

Falsedad propia (Art. 427, primer párrafo CP).

Tipicidad Objetiva. El objeto material del delito es el documento. Se entiende por documento toda declaración materializada, procedente de una persona que figura como su autor, cuyo contenido tiene eficacia probatoria en el ámbito del tráfico jurídico.

De la definición planteada se puede deducir que los elementos básicos de todo documento son: la mención del autor, circunstancia que conecta directamente con la autenticidad del documento (documento auténtico es aquel que procede de la persona que figura en él como autor); forma (lo que nos llevaría a la interesante problemática de que en la actualidad sea suscrita en torna a la posibilidad de incluir al documento informático como objeto material de este delito), y contenido, que, según se deduce de lo dispuesto en el artículo 427 del Código Penal, consistiría en la constitución de un derecho y obligación o simplemente en cualquier hecho para el cual el documento esté destinado a probar (en relación con esto se habla de veracidad del documento, de tal forma que documento verdadero o verídico sería aquel cuyo contenido coincide con el objeto cierto para cuya constatación el documento ha sido realizado).

El Código Penal menciona distintas categorías de documentos: documento público, registros públicos, título auténtico o cualquier otro transmisible por endoso o al portador de documento privado. Todas estas categorías son reconducibles a dos básicas: público y documento privado.

21 Luis Alberto Bramont-Arias Torres; María del Carmen García Cantizano. Manual de Derecho Penal. Parte especial. Segunda reimpresión. Lima: Editorial San Marcos, 2010. 
Por documento público se entiende aquel que ha sido formalizado de acuerdo con los requisitos legales establecidos por cualquier funcionario que ejerza las labores de fedatario público. Dentro del documento público debe entenderse incluido el registro público.

Sin embargo, el Código Penal equipara a documentos públicos el testamento ológrafo y cerrado, los títulos valores y los títulos de créditos transmisibles por endoso o al portador, títulos auténticos (Art. 433 del CP). Es decir, a efectos de penal, tales documentos quedan equiparados al documento público, aunque en realidad no lo sean.

Documento privado es todo aquel que no está incluido dentro del concepto de documento público.

El comportamiento consiste en hacer, en todo o en parte, un documento falso o adulterar uno verdadero que pueda dar origen a derecho u obligación o servir para probar un hecho.

Por tanto, el comportamiento se puede realizar de dos maneras:

a) Hacer en todo o en parte un documento falso. Consiste en la realización en general de un documento falso. Sujeto activo puede ser en principio cualquiera, con excepción del autor del documento en los supuestos de realización de un documento enteramente falso, puesto que, en este último caso, el documento en sí será siempre genuino, en la medida en que el documento recoge lo que efectivamente el autor ha puesto; no respondería por este delito, aunque, sí por ejemplo, de estafa, de concurrir los demás elementos típicos de este delito. Sujeto pasivo es la colectividad.

Por realizar un documento falso se entiende la creación de un documento que no existía anteriormente, en donde se hacen constar derechos, obligaciones o hechos que no corresponden con el contenido cierto que el documento debería constar. Sin embargo, es necesario precisar que no puede identificarse realizar un documento enteramente falso a la realización de un documento solo en parte falso, puesto que esta última conducta estaría ya abarcada por la segunda modalidad típica comprendida en el artículo de análisis. Es decir, quien altera solo en parte el contenido de un documento también está realizando un documento en parte falso.

b) Adulterar uno verdadero: sujeto activo puede ser cualquier persona. Sujeto pasivo es la colectividad.

A diferencia del comportamiento anterior, aquí es necesaria la previa existencia de un documento verdadero. El comportamiento se realiza cuando se adultera, esto es, se altera dicho documento. Por ejemplo, la alteración de la fecha o cantidad en un contrato o en una letra de cambio.

Tipicidad subjetiva. Se requiere el dolo, es decir, el conocimiento y voluntad de hacer un 
documento falso o adulterar uno verdadero. Además, se exige un elemento subjetivo del tipo que es el propósito de utilizar el documento, es decir, la finalidad de emplear dicho documento en el tráfico jurídico. Dada la redacción de la conducta del Art. $427^{\circ} \mathrm{CP}$, pareciera que no se incluye dentro del elemento subjetivo del tipo la finalidad de causar un perjuicio mediante el empleo del documento, sino que sería una condición objetiva de punibilidad.

Grados de desarrollo del delito: tentativa y consumación. El delito se consuma con la realización de un documento falso o la adulteración de uno verdadero. Por lo tanto, no se requiere que el sujeto activo emplee dicho documento, es decir, que lo introduzca en el tráfico jurídico, siendo suficiente con que tenga dicho propósito.

No hay inconveniente en admitir la tentativa; por ejemplo, el cajero de un banco que sorprende a una persona borrando la cantidad o la fecha del cheque.

\section{Falsedad impropia o falsedad de uso (Art. 427, segundo párrafo del CP)}

Tipicidad objetiva. Sujeto activo puede ser cualquier persona, con excepción del autor del delito precedente o del partícipe en él. Sujeto pasivo es la colectividad.

El objeto material de este delito es un documento falso o falsificado, extendido por aquel que resulta ser el producto de las anteriores conductas ya descritas.

El comportamiento consiste en hacer uso de un documento falso o falsificado. Por hacer uso de un documento se entiende emplear, utilizar el documento falso o falsificado como si fuese legítimo, es decir, para los fines que hubiera servido de ser un documento auténtico o cierto.

Tipicidad subjetiva. Se requiere el dolo, es decir, el conocimiento y voluntad de utilizar un documento falso o falsificado, abarcando además la intención de emplearlo como si fuera legítimo, circunstancia esta que no constituye elemento subjetivo del tipo, distinto del dolo.

Grados de desarrollo del delito: tentativa y consumación. El delito se consuma con el uso o empleo del documento falso o falsificado, esto es, con la introducción del objeto material en el seno del tráfico jurídico. La posesión del documento, previa al uso, ya sería constitutiva de tentativa.

Condición objetiva de punibilidad. Al incluirse una condición objetiva de punibilidad, se está indicando que el hecho es típico y antijurídico, y que el sujeto activo es culpable. Pero además, y por razones de políticas criminal, se exige para la punibilidad que del uso del documento pueda resultar un perjuicio; en caso contrario, el hecho no se castigará.

En la práctica, la razón por la que los casos de falsificación de documentos llegan al Poder Judicial estriba en la comisión de un perjuicio, por lo que esta condición objetiva de punibilidad no genera mayores problemas de aplicación. 
Agravante. Se recoge expresamente una circunstancia que agrava la pena en función de la calidad del sujeto activo, es decir, si es funcionario o servidor público o notario que actúa con abuso de sus funciones (art. 432 del CP).

La pena. En caso de falsificación de documentos públicos o de su uso, se establece pena privativa de libertad no menor de dos ni mayor de diez años y treinta a noventa días-multa.

Para el caso de falsificación de documentos privado o de su uso, se establece pena privativa de libertad no menor de dos ni mayor de cuatro años, y ciento ochenta a trescientos sesenta y cinco días-multa.

En caso de que concurra el agravante, además de las penas indicadas, se castigará con pena de inhabilitación de uno a tres años (art. 36, 1 y 2 CP).

\section{EL PERJUICIO EN LOS DELITOS DE FALSEDAD DOCUMENTAL}

El perjuicio debe estar relacionado con una falsedad. Y en este aspecto es oportuno señalar alguna aclaración. El perjuicio o daño en una escritura pública no es el que resulta de violar la fe pública a través de la función de autenticar que el oficial está encargado de cumplir, sino el de la violación de algún otro bien jurídico. La circunstancia de que la falsedad en instrumento público se consuma en cuanto el documento queda perfeccionado, en tanto que para los papeles privados se retrasa ese momento hasta que son usados, no significa que la posibilidad de perjuicio resulta ya del hecho mismo de que la escritura sea pública, sino que, para el caso en que la posibilidad de perjuicio exista, el hecho está perfeccionado con la confección del documento, que desde ese momento vale por sí mismo y puede ser opuesto a terceros, lo que no ocurre con los papeles privados. De otra parte, la posibilidad de perjuicio debe resultar de la escritura misma y ser abarcada por el dolo del autor, con prescindencia del uso que del documento pueda hacer un tercero, de modo que del hecho de él (del tercero) sea del que resulte el perjuicio o su posibilidad. ${ }^{22}$

\section{CASUÍSTICA DE JURISPRUDENCIA PENAL. ${ }^{23}$ "ELABORACIÓN” DE UNA ESCRITURA PÚBLICA POR DOS SUJETOS SE ACREDITA CON LA CONDENA DEL PRIMERO}

Se condenó a dos ciudadanos en diversos momentos por haber elaborado, en concierto de voluntades, un testimonio de escritura pública de compraventa respecto de un bien inmueble, para utilizarlo en un proceso judicial de desalojo instaurado en contra del agraviado.

El procesado que fue condenado en segundo lugar interpuso recurso de apelación

22 Carlos Fontana Balestra. Tratado de Derecho Penal. Parte especial. Tomo VII. Buenos Aires: Abeledo-Perrot.

23 Casuística de jurisprudencia penal. Primera edición. Lima: Gaceta Jurídica S. A., 2010. 
sosteniendo que no se había probado la comisión del delito imputado, lo cual le causa desmedro y detrimento. Así mismo, que se desconoció el debido proceso y que la reparación civil fijada le resulta onerosa.

$\mathrm{Al}$ existir una condena previa al coprocesado por los mismos hechos, quien expresó además su conformidad respecto de la sentencia que lo condena, la Sala Superior de manera implícita corrobora las imputaciones formuladas en contra del recurrente, esto es, el hecho de que ambos agentes, en concierto de voluntades, procedieron a la elaboración del testimonio de escritura pública de compraventa respecto de un bien inmueble para utilizarlo en un proceso judicial de desalojo.

Así mismo, la Sala Superior considera que la sentencia se encuentra corroborada con la propia declaración instructiva del procesado, quien admitió haberse encargado del proceso judicial de desalojo, solicitando para tal propósito una suma económica (cien nuevos soles). Igualmente, se evidencia la participación de este agente en el trámite del proceso judicial de desalojo por el manuscrito de proforma emitido por el recurrente respecto de los costos de tramitación de la demanda de desalojo aludida, así como por un voucher bancario por pago de tasa judicial, en cuyo reverso aparece su nombre.

De esta forma se concluye que en autos está acreditada la materialización de los delitos de fraude procesal y falsificación de documentos, previstos en los artículos 416 y 427 del Código Penal y la responsabilidad del recurrente.

Respecto a la reparación civil, la Sala Superior precisa que cuando se trata de procesos en los que exista pluralidad de acusados por el mismo hecho y estos sean sentenciados de manera sucesiva, es decir, independientemente, por diferentes circunstancias contempladas en nuestro ordenamiento procesal penal, la reparación civil a imponer para todos debe ser fijada en la primera sentencia firme. Por lo tanto, al existir sentencia firme que impone como reparación civil una suma a favor de cada uno de los agraviados, la reparación civil impuesta al recurrente debe ser igual a la antes señalada ${ }^{24}$.

24 Sala Especializada en lo Penal para procesos con reos libres de la Corte Superior de Justicia de Huacho. Exp. N ${ }^{\circ} 281$ 2001-FL 292. Resolución No 49 (Data 45:000). Denunciante: Luis Alberto Aldave Flores. Agraviados: el Estado, Alfredo Aparicio Valdez y otros. Asunto: falsificación de documentos y fraude procesal. Fecha: 28 de setiembre de 2007. 


\section{CONCLUSIONES}

1. Del análisis realizado respecto al delito de falsificación de documentos, se debe señalar que la antijuricidad se manifiesta en el actuar contrario a la fe pública, faltando a la confianza, certeza y seguridad jurídica representada en el documento público.

2. Según la forma en que el legislador ha desarrollado el delito de falsificación de documentos en el Art. $427^{\circ}$ del Código Penal, es difícil probar la comisión del delito por la mala redacción de la proposición normativa en el supuesto de hecho, y por imperio del principio constitucional, la duda favorece al reo, las conductas ilícitas queden impunes, siendo esto un aliciente al delincuente para seguir en su accionar ilícito en perjuicio de la paz social.

3. Es necesario uniformizar criterios doctrinales y jurisprudenciales con la finalidad de determinar el bien jurídico o bienes jurídicos sujetos de protección de la ley penal.

4. Teniendo en cuenta que el Derecho Penal es la última ratio y medio de control social formal, se deben dictar medidas preventivas antes que sancionadoras, debiendo para ello delimitar con claridad y exactitud lo que debe entenderse por documento dentro del ámbito penal.

5. Considerando el uso que de los avances tecnológicos hace el delincuente para la falsificación de documentos, resulta necesario que el Estado implemente una política criminal avocada a establecer las nuevas modalidades delictivas en la norma penal.

\section{REFERENCIAS}

- Bramont-Arias, Luis A. "Falsedad", en Enciclopedia Jurídica OMEBA. Tomo XI. Buenos Aires, 1979.

- Bramont-Arias Torres, Luis Alberto; García Cantizano, María del Carmen. Manual de Derecho Penal. Parte especial. Segunda reimpresión. Lima: Editorial San Marcos, 2010.

- Bustos Ramírez, Juan. Manual de Derecho Penal. Parte especial. 2da. edición. Barcelona: Ariel, 1991.

- Casuistica de jurisprudencia penal. Primera edición. Lima: Gaceta Jurídica S. A., 2010.

- Cuello Calón, Eugenio. Derecho Penal. Parte especial. Tomo II. Decimocuarta edición. Barcelona: Bosch, Casa Editorial S. A., 1980.

- Dona, Edgardo. "El bien jurídico en los delitos contra la fe pública”. En Modernas tendencias 
en dogmática penal y política criminal, ed. Urquizo Olaechea. Libro de homenaje al doctor Juan Bustos Ramírez. Lima: Idemsa, año 2007.

- Fontana Balestra, Carlos. Tratado de Derecho Penal. Parte especial. Tomo VII. Buenos Aires: Abeledo-Perrot.

- Mir Puig, Santiago. Derecho Penal. Parte general. 4ta. edición corregida y puesta al día con arreglo al Código Penal de 1995. Barcelona: PPU S. A., 1996.

- Muñoz Conde. Derecho Penal. Parte especial. Valencia: Tirant lo Blanch, 1999.

- Rosales Artica, David. "El delito de falsificación de documentos. Bien jurídico y objeto material de la acción". Actualidad Jurídica, tomo 160 (marzo 2007).

- Urtecho Benites, Santos Eugenio. El perjuicio en los delitos de falsedad documental. Consecuencias de la proposición ambigua del tipo legal e interpretación teórica deficiente. Segunda edición, corregida, aumentada y actualizada. Lima, Perú: Idemsa, 2015.

- Viveros Castellanos, Yesid. Falsedad ideológica. Bogotá, Colombia: Ediciones Doctrina y Ley Ltda., 2006. 